\title{
Correction to: Purification of Cyclin-Dependent Kinase Fusion Complexes for In Vitro Analysis
}

\section{Mardo Kõivomägi}

Correction to: Chapter 8 in: Amanda S. Coutts (ed), Cell Cycle Oscillators: Methods and Protocols, Methods in Molecular Biology, vol. 2329, https://doi.org/10.1007/978-1-0716-1538-6_8

In the original version of this book, chapter 8 was published with a typographical error in chapter title. This has been updated in the revised version of this book.

The updated online version of these chapters can be found at https://doi.org/10.1007/978-1-0716-1538-6_8 